Journal Club

Editor's Note: These short reviews of recent JNeurosci articles, written exclusively by students or postdoctoral fellows, summarize the important findings of the paper and provide additional insight and commentary. If the authors of the highlighted article have written a response to the Journal Club, the response can be found by viewing the Journal Club at www.jneurosci.org. For more information on the format, review process, and purpose of Journal Club articles, please see http://www.jneurosci.org/content/ jneurosci-journal-club.

\title{
Dnmt3a2 in the Nucleus Accumbens Shell Mediates Cue-Induced Cocaine-Seeking Behavior
}

\author{
타ad Lax and Doniel M. Sapozhnikov \\ Department of Pharmacology and Therapeutics, McGill University, Montreal, Quebec H3G 1Y6, Canada \\ Review of Cannella et al.
}

One of the main obstacles in treating drug addiction is the high rates of relapse even after prolonged periods of abstinence. Neuronal adaptions play a major role in drug craving and relapse (Kalivas and Volkow, 2005). Many of these adaptions involve changes in gene expression (Nestler, 2001), which in turn are mediated by epigenetic modifications. For example, DNA methylation is a fundamental epigenetic mechanism of gene expression regulation, and several studies have found DNA methylation patterns to change following drug exposure. Furthermore, pharmacological or genetic manipulation of the DNA methylation state can alter cocaine-seeking behavior (LaPlant et al., 2010; Massart et al., 2015).

The three mammalian DNA methyltransferases (Dnmt1, Dnmt3a, and Dnmt3b) catalyze the addition of methyl groups to cytosines in DNA. Of these, DNMT1 is considered to act primarily as a "maintenance" methyltransferase by copying the CpG methylation patterns from parental DNA strands to daughter strands during DNA replication. In contrast, Dnmt3a

Received Oct. 6, 2018; revised Jan. 23, 2019; accepted Feb. 4, 2019.

E.L. was supported by the Richard and Edith Strauss Canada Fund Postdoctoral Fellowship in Medicine, McGill University. D.M.S. was supported Natural Sciences and Engineering Research Council of Canada Discovery Grants Program and the Faculty of Medicine, McGill University J.P. Collip Fellowship.

The authors declare no competing financial interests. Correspondence should be addressed to Elad Lax at eladlax@mail.mcgill.ca. https://doi.org/10.1523/JNEUROSCI.2584-18.2019

Copyright $@ 2019$ the authors and Dnmt3b are de novo methyltransferases that can produce novel methyl marks independently of DNA replication and are therefore the enzymes principally responsible for altering DNA methylation patterns in response to environmental events, such as drug exposure. Moreover, several animal studies have indicated that Dnmt3a is an important regulator of cocaine-seeking behavior (LaPlant et al., 2010; Massart et al., 2015), chronic stress (LaPlant et al., 2010), and learning and memory (Day et al., 2013; Morris et al., 2014). Notably, the Dnmt3a2 isoform of the Dnmt3a gene has a unique DNA localization pattern and a distinctive DNA methylation behavior different from that of the longer isoform, Dnmt3a1 (Manzo et al., 2017; Bozic et al., 2018). Dnmt3a2 localizes primarily to transcription-accessible DNA (i.e., euchromatin), possesses de novo DNA methyltransferase activity, and contributes to memory formation and maintenance (Chen et al., 2002; Oliveira et al., 2012, 2016).

Considering these findings, Cannella et al. (2018) sought to investigate the potential role of Dnmt3a2 in addictive behavior. In a set of cocaine self-administration experiments in rats, the authors found that Dnmt3a2 expression increased after cue-induced reinstatement of cocaine-seeking, but not after cocaine selfadministration or extinction. Moreover, viral knockdown of Dnmt3a2 in the NAc shell reduced cue-induced reinstatement without affecting self-administration. These findings suggest that Dnmt3a2 has a role in cue-induced reinstatement but does not mediate the reinforcing effects of cocaine. Furthermore, the beneficial effect of Dnmt3a2 knockdown on cueinduced cocaine-seeking was preserved even after a long incubation time (45 d) when cocaine-seeking behavior is typically amplified.

As cocaine can modify behaviors by inducing dopamine release onto medium spiny neurons in the NAc shell, a structure involved in the reinstatement of cocaineseeking (Anderson et al., 2006; Cruz et al., 2014), the authors investigated whether dopaminergic signaling regulates Dnmt3a expression in these neurons. Indeed, the authors showed that Dnmt3a2, and not Dnmt3a1, was induced after pharmacological activation of D1 dopamine receptors of cultured medium spiny neurons and that the ensuing increase in expression of the immediate early genes (IEGs) $A r c, F o s B$, and Egr2 was prevented by knockdown of Dnmt3a2. Importantly, acute in vivo injection of cocaine into the NAc shell increased expression of Dnmt3a2, Arc, FosB, and Egr2 in this region: a pattern similar to that seen after activation of D1 dopamine receptors. Nonetheless, the authors state that the induction of Dnmt3a2 expression by cocaine in vivo cannot be responsible for the upregulation of the IEGs because Dnmt3a2 expression increased $6 \mathrm{~h}$ after 
D1 agonism in vitro, whereas IEG activation was observed as soon as $1 \mathrm{~h}$ after agonist treatment.

Why then does prior knockdown of Dnmt3a2 prevent upregulation of IEGs upon dopamine agonism? The authors suggest that Dnmt3a2 acts on the DNA before the stimulus, performing a "gating function" that sets the IEGs in a state that permits subsequent dopamine-induced gene expression. For example, the modification of DNA methylation by Dnmt3a2 might alter recruitment of transcription factors to regulatory genetic loci. The presence or absence of specific transcription factors might then alter the response induced by a later stimulus, such as increasing IEG expression shortly after dopaminergic transmission.

While this is a reasonable explanation, it is important to consider the possibility that Dnmt3a2 does induce these genes within the same stimulus. The delay in increase in Dnmt3a2 expression relative to the more rapid increase in IEG expression is observational, and not experimental data. When Dnmt3a2 is experimentally depleted by knockdown, Dnmt3a2 protein levels are already reduced at the time of stimulus. Therefore, if cocaine treatment or dopaminergic transmission can, like other documented physiological manipulations (Jeltsch and Jurkowska, 2016), modify the binding or activity of Dnmt3a2 at IEG regulatory regions, then experimental depletion of Dnmt3a2 protein would be expected to affect IEG expression within the same stimulus. A reduced level of Dnmt3a2 protein may now be insufficient to adequately respond to the stimulus to produce IEG expression changes. The observation that Dnmt3a2 gene expression increases only after IEG expression should be considered independently from possible Dnmt3a2 protein function and could be mechanistically irrelevant to IEG induction. The late D1 receptor-induced Dnmt3a2 expression changes could instead be a consequence of global gene expression changes upon dopaminergic transmission or of an autogenous regulatory circuit in which the Dnmt3a2 protein regulates the expression of its own promoter, either directly or indirectly (Goldberger, 1974). Therefore, it is important to note that the observational data presented by Cannella et al. (2018) do not necessarily suggest that Dnmt3a2 cannot increase IEG expression within the same stimulus.

Previous work has shown that increased DNA methylation by DNA methyltransferases is usually associated with gene repression. While DNA methylation levels were not measured by Cannella et al. (2018), it is reasonable to assume that downregulation of Dnmt $3 a 2$ results in hypomethylation of the DNA and therefore increased gene expression. Surprisingly, however, the expression levels of all three IEGs instead correlated positively with Dnmt3a2 levels and unexpectedly decreased following Dnmt3a2 knockdown. The authors suggest that this phenomenon may occur because DNA methylation is classically associated with gene repression when it occurs in the context of gene promoters and that changes in DNA methylation in response to cue-induced cocaine-seeking might occur outside of the promoters of the IEGs. This is a rational explanation because Dnmt3a2 activity can potentially target gene bodies, which are generally highly methylated in transcriptionally active genes, presumably to prevent aberrant transcriptional initiation from alternative or ambiguous promoters, which may produce transcripts with alternative or defective functionality. Associations between gene-body demethylation and aberrant transcription initiation have been observed in both human and mouse brains (Maunakea et al., 2010) as well as in other tissues (Neri et al., 2017). Increased gene body methylation can, in turn, increase expression from canonical promoters by concentrating transcriptional machinery at these promoters.

The notion that gene-body methylation may be responsible for the observations by Cannella et al. (2018) is supported by previous findings that Dnmt3a can methylate nonpromoter DNA to facilitate expression of neurogenic genes and thereby contribute to postnatal neurogenesis (Wu et al., 2010). A more recent study (Manzo et al., 2017) found that Dnmt3a1 in neurons preferentially binds to CpGs in promoters occupied by both active and repressive histone marks, known as bivalent promoters; of particular significance is the fact that this promoter preference is mediated through an N-terminal region of Dnmt3a1, which is not incorporated into Dnmt3a2. The absence of the longer $\mathrm{N}$-terminal region in Dnmt3a2 permits broader binding of Dnmt3a2 to CpGs throughout the genome. It is therefore plausible that Dnmt3a2 is responsible for most nonpromoter Dnmt3a-mediated DNA methylation in the brain, including gene-body methylation of the IEGs analyzed by Cannella et al. (2018).

It is important to note that Dnmt3a2 does not recognize a specific DNA con- sensus sequence (Manzo et al., 2017); therefore, it probably acts to methylate gene promoters as well. Consequently, an alternative interpretation of the data provided by Cannella et al. (2018) is that the transcriptional changes seen upon cocaine exposure are indeed mediated by the activity of Dnmt3a2 on the IEG promoters. Although in most cases methylated DNA prevents the binding of transcription factors (Moore et al., 2013), some transcription factor families, such as $\mathrm{C} / \mathrm{EBP}, \mathrm{NKX}, \mathrm{PAX}$, and HOXA, instead bind preferentially to methylated DNA (Hu et al., 2013; Chatterjee et al., 2014; Yin et al., 2017). We therefore inspected the DNA sequences upstream of the $A r c$, FosB, and Egr 2 transcription start sites for the presence of predicted binding sites for these transcription factors using the PROMO software (Messeguer et al., 2002). This revealed that all three IEG promoters bear CpG-containing consensus binding sites for transcription factors that preferentially bind methylated DNA. It is therefore possible that, during cocaine exposure, increased levels of Dnmt3a2 lead to hypermethylation of these sites, thereby increasing binding of transcription factors that prefer methylated CpGs, and ultimately leading to gene activation.

Further experiments can clarify the mechanism(s) by which Dnmt3a2 increases IEG expression after cocaine exposure. An ideal strategy would involve a combination of two experimental approaches: (1) chromatin immunoprecipitation of Dnmt3a2 after cocaine exposure or cue-induced cocaine-seeking to determine the genomic location of Dnmt3a2 activity; and (2) targeted bisulfite-sequencing of genomic loci within and around the IEGs analyzed in this study to define with single-nucleotide resolution the DNA methylation state of these genes in the context of cocaine-induced Dnmt3a2 activity. If cocaine exposure leads to Dnmt3a2 binding and DNA hypermethylation within gene bodies, it will confirm that Dnmt3a2 increases cocaine-induced IEG expression through nonpromoter DNA methylation and possibly inhibition of alternative promoters. If, on the other hand, Dnmt3a2 instead also binds and hypermethylates gene promoters, it will suggest the involvement of transcription factors that preferentially bind methylated DNA in the promoter, and further chromatin immunoprecipitation experiments could determine which of these transcription factors are recruited. This feasible strategy could provide crucial supplementary insight into the mecha- 
nisms by which Dnmt3a2 activity promotes the expression of Arc, Fosb, and Egr2, which are involved in cocaineseeking behavior (Gao et al., 2017). This approach might also reveal altered transcription of other Dnmt3a2-regulated genes upon cue-induced cocaine-seeking.

\section{References}

Anderson SM, Schmidt HD, Pierce RC (2006) Administration of the D2 dopamine receptor antagonist sulpiride into the shell, but not the core, of the nucleus accumbens attenuates cocaine priming-induced reinstatement of drug seeking. Neuropsychopharmacology 31:14521461.

Bozic T, Frobel J, Raic A, Ticconi F, Kuo CC, Heilmann-Heimbach S, Goecke TW, Zenke M, Jost E, Costa IG, Wagner W (2018) Variants of DNMT3A cause transcript-specific DNA methylation patterns and affect hematopoiesis. Life Sci Alliance. 13:e201800153.

Cannella N, Oliveira AM, Hemstedt T, Lissek T, Buechler E, Bading H, Spanagel R (2018) Dnmt3a2 in the nucleus accumbens shell is required for reinstatement of cocaine-seeking. J Neurosci 38:7516-7528.

Chatterjee R, He X, Huang D, FitzGerald P, Smith A, Vinson C (2014) High-resolution genomewide DNA methylation maps of mouse primary female dermal fibroblasts and keratinocytes. Epigenetics Chromatin 7:35.

Chen T, Ueda Y, Xie S, Li E (2002) A novel Dnmt3a isoform produced from an alternative promoter localizes to euchromatin and its expression correlates with active de novo methylation. J Biol Chem 277:38746-38754.

Cruz FC, Babin KR, Leao RM, Goldart EM, Bossert JM, Shaham Y, Hope BT (2014) Role of nucleus accumbens shell neuronal ensembles in context-induced reinstatement of cocaine-seeking. J Neurosci 34:7437-7446.

Day JJ, Childs D, Guzman-Karlsson MC, Kibe M,
Moulden J, Song E, Tahir A, Sweatt JD (2013) DNA methylation regulates associative reward learning. Nat Neurosci 16:1445-1452.

Gao P, Limpens JH, Spijker S, Vanderschuren LJ, Voorn P (2017) Stable immediate early gene expression patterns in medial prefrontal cortex and striatum after long-term cocaine self-administration. Addict Biol 22:354-368.

Goldberger RF (1974) Autogenous regulation of gene expression. Science 183:810-816.

Hu S, Wan J, Su Y, Song Q, Zeng Y, Nguyen HN, Shin J, Cox E, Rho HS, Woodard C, Xia S, Liu S, Lyu H, Ming GL, Wade H, Song H, Qian J, Zhu H (2013) DNA methylation presents distinct binding sites for human transcription factors. Elife 2:e00726.

Jeltsch A, Jurkowska RZ (2016) Allosteric control of mammalian DNA methyltransferases: a new regulatory paradigm. Nucleic Acids Res 44:8556-8575.

Kalivas PW, Volkow ND (2005) The neural basis of addiction: a pathology of motivation and choice. Am J Psychiatry 162:1403-1413.

LaPlant Q, Vialou V, Covington HE 3rd, Dumitriu D, Feng J, Warren BL, Maze I, Dietz DM, Watts EL, Iñiguez SD, Koo JW, Mouzon E, Renthal W, Hollis F, Wang H, Noonan MA, Ren Y, Eisch AJ, Bolanos CA, Kabbaj M, et al. (2010) Dnmt3a regulates emotional behavior and spine plasticity in the nucleus accumbens. Nat Neurosci 13:1137-1143.

Manzo M, Wirz J, Ambrosi C, Villaseñor R, Roschitzki B, Baubec T (2017) Isoform-specific localization of DNMT3A regulates DNA methylation fidelity at bivalent $\mathrm{CpG}$ islands. EMBO J 36:3421-3434.

Massart R, Barnea R, Dikshtein Y, Suderman M, Meir O, Hallett M, Kennedy P, Nestler EJ, Szyf M, Yadid G (2015) Role of DNA methylation in the nucleus accumbens in incubation of cocaine craving. J Neurosci 35:8042-8058.

Maunakea AK, Nagarajan RP, Bilenky M, Ballinger TJ, D'Souza C, Fouse SD, Johnson BE, Hong C, Nielsen C, Zhao Y, Turecki G, Delaney A, Varhol R, Thiessen N, Shchors K,
Heine VM, Rowitch DH, Xing X, Fiore C, Schillebeeckx M, et al. (2010) Conserved role of intragenic DNA methylation in regulating alternative promoters. Nature 466:253-257.

Messeguer X, Escudero R, Farré D, Núñez O, Martínez J, Albà MM (2002) PROMO: detection of known transcription regulatory elements using species-tailored searches. Bioinformatics 18:333-334.

Moore LD, Le T, Fan G (2013) DNA methylation and its basic function. Neuropsychopharmacology 38:23-38.

Morris MJ, Adachi M, Na ES, Monteggia LM (2014) Selective role for DNMT3a in learning and memory. Neurobiol Learn Mem 115:30-37.

Neri F, Rapelli S, Krepelova A, Incarnato D, Parlato C, Basile G, Maldotti M, Anselmi F, Oliviero S (2017) Intragenic DNA methylation prevents spurious transcription initiation. Nature 543:72-77.

Nestler EJ (2001) Molecular basis of long-term plasticity underlying addiction. Nat Rev Neurosci 2:119-128.

Oliveira AM, Hemstedt TJ, Bading H (2012) Rescue of aging-associated decline in Dnmt3a2 expression restores cognitive abilities. Nat Neurosci 15:1111-1113.

Oliveira AM, Hemstedt TJ, Freitag HE, Bading H (2016) Dnmt3a2: a hub for enhancing cognitive functions. Mol Psychiatry 21:1130-1136.

Wu H, Coskun V, Tao J, Xie W, Ge W, Yoshikawa K, Li E, Zhang Y, Sun YE (2010) Dnmt3adependent nonpromoter DNA methylation facilitates transcription of neurogenic genes. Science 329:444-448.

Yin Y, Morgunova E, Jolma A, Kaasinen E, Sahu B, Khund-Sayeed S, Das PK, Kivioja T, Dave K, Zhong F, Nitta KR, Taipale M, Popov A, Ginno PA, Domcke S, Yan J, Schubeler D, Vinson C, Taipale J (2017) Impact of cytosine methylation on DNA binding specificities of human transcription factors. Science 356: 6337 